\title{
PECTINA LIASE DE Aspergillus niger ATCC 9642 IMOBILIZADA IN SITU EM ESPUMA DE POLIURETANO
}

\author{
C. M. BOCALON ${ }^{1}$, J. ZENI ${ }^{1}$, J. PILI ${ }^{1}$, G. T. BACKES ${ }^{1}$, E. VALDUGA ${ }^{1}$, A. C. \\ SCHUMANN $^{1}$, J. COLLA ${ }^{1}$, N. L. D. NYARI ${ }^{1}$ \\ ${ }^{1}$ Universidade Regional Integrada do Alto Uruguai e das Missões, Departamento de \\ Engenharia de Alimentos \\ E-mail para contato: jamilezeni@uricer.edu.br
}

\begin{abstract}
RESUMO - Neste trabalho objetivou-se imobilizar a pectina liase produzida por Aspergillus niger ATCC 9642 em poliuretano e avaliar a estabilidade térmica da enzima imobilizada. A pectina liase empregada neste estudo foi bioproduzida por fermentação submersa utilizando Aspergillus niger ATCC 9642 em médio sintético composto por $32 \mathrm{~g} / \mathrm{L}$ de pectina cítrica (VETEC), $2 \mathrm{~g} / \mathrm{L}$ de L-asparagina, $0,06 \mathrm{~g} / \mathrm{L}$ de fosfato de potássio, $1,0 \mathrm{~g} / \mathrm{L}$ de sulfato de ferro, $180 \mathrm{rpm} 30^{\circ} \mathrm{C}, \mathrm{pH}$ inicial de 5,5 e 48 horas de fermentação. A reação de polimerização para obtenção do poliuretano (PU) foi realizada utilizando a razão dos monômeros poliol:isocianato $(6: 4(\mathrm{v} / \mathrm{v}))$ e $1 \mathrm{~mL}$ de enzima diluída previamente em água (1:10 $\mathrm{v} / \mathrm{v})$ ). A fim de avaliar o processo de imobilização, realizaram-se os cálculos do rendimento da imobilização, cujo resultado foi de 1042,06\%. A avaliação da estabilidade térmica da enzima imobilizada foi avaliada incubando-se a enzima imobilizada a diferentes temperaturas $\left(-80,-2,2-8,10-25\right.$ e $\left.35^{\circ} \mathrm{C}\right)$ em função do tempo de estocagem. De acordo com os resultados apresentados, a PMGL imobilizada é mais estável a temperatura de $35^{\circ} \mathrm{C}$, apresentando $50 \%$ de sua atividade após 50 dias de estocagem.
\end{abstract}

\section{INTRODUÇÃO}

As enzimas pectinolíticas constituem um complexo sistema de biocatalisadores, cuja função é a degradação ou modificação das substâncias pécticas (YADAV et al., 2009). As pectinases têm diferentes aplicações biotecnológicas em indústria de bebidas (auxilia no processo de filtração, clarificação e aumento do rendimento), indústria de alimentos (fermentação de café e chá e extração de óleo), indústria têxtil (degomagem de fibras algodão, rami, juta e linho), ração animal e indústria de papel e celulose (SANDRI et al., 2011; ZHANG et al., 2011; DÍAZ et al., 2013; PEREZ et al., 2013).

A pectina liase (PMGL) é uma enzima que despolimeriza a pectina com alto grau de metoxilação diretamente por $\beta$-eliminação, resultando a formação de ácido galacturônico com uma insaturação entre os carbonos 4 e 5 do final não redutor do ácido galacturônico formado, causando uma rápida queda na viscosidade da solução do substrato. Esta enzima é particularmente interessante por despolimerizar pectinas sem alterar seu grau de esterificação e sem a necessidade de ação prévia de outra enzima do complexo pectinolítico (YADAV et al., 2009).

Por razões práticas e econômicas, o reuso de enzimas (e da pectina liase, em particular) deve também ser considerado. Para resolver este problema, nas últimas décadas foram 


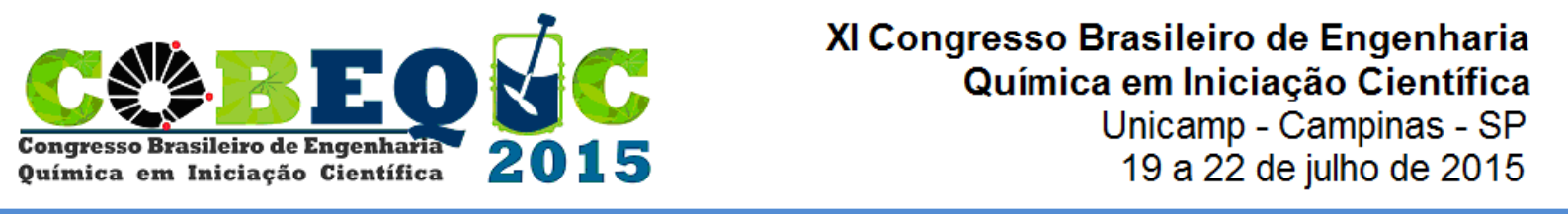

desenvolvidos métodos de imobilização. O uso da tecnologia para imobilizar enzimas ganhou impulso por várias razões. Uma das principais vantagens é que ela permite a reciclagem e reutilização fácil, o que melhora significativamente a viabilidade comercial da enzima em comparação com a enzima livre (Milner et al., 2013).

A imobilização envolve tipicamente a fixação ou dispersão de uma enzima ou célula em um material insolúvel, para formar um sistema heterogêneo. Os métodos de imobilização são, em geral, usados para proteger a enzima do meio reacional (aquoso, orgânico, ou aquorrestrito), promovendo assim a manutenção ou o aumento significativo na atividade catalítica. Além disso, outros benefícios são o aumento da uma maior estabilidade em valores de $\mathrm{pH}$ e de temperaturas diferentes, facilidade de controle de reação e separação do produto final (Sheldon e Van Pelt, 2013).

Neste sentido, este trabalho teve como objetivo imobilizar a pectina liase produzida por Aspergillus niger ATCC 9642 em poliuretano e avaliar a estabilidade térmica da enzima imobilizada.

\section{METODOLOGIA}

\subsection{Produção da Pectina liase (PMGL)}

A pectina liase empregada neste estudo foi bioproduzida por fermentação submersa utilizando Aspergillus niger ATCC 9642 em médio sintético composto por $32 \mathrm{~g} / \mathrm{L}$ de pectina cítrica (VETEC), $2 \mathrm{~g} / \mathrm{L}$ de L-asparagina, $0,06 \mathrm{~g} / \mathrm{L}$ de fosfato de potássio, 1,0 g/L de sulfato de ferro, $180 \mathrm{rpm} 30^{\circ} \mathrm{C}$, pH inicial de 5,5 e 48 horas de fermentação (Gomes et al., 2011).

\subsection{Imobilização}

A imobilização foi realizada utilizando a pectina liase produzida conforme citado anteriormente. A enzima PMGL foi previamente diluída em $\mathrm{H}_{2} \mathrm{O}$, na proporção de $1: 10(\mathrm{v} / \mathrm{v})$ (enzima:água). Os monômeros comerciais poliol e isocianato foram produzidos com uma formulação específica para colchões e espumas injetadas, pela Empresa Flexível PoliuretanosMannes.

A reação de polimerização para obtenção do poliuretano (PU) foi realizada utilizando a razão dos monômeros poliol:isocianato $(6: 4(\mathrm{v} / \mathrm{v}))$, segundo metodologia de Nyari et al., (2013).

O procedimento de imobilização da enzima PMGL em PU foi realizada na concentração pré-estabelecida da etapa anterior, onde $10 \%$ da enzima diluída foi adicionada ao monômero (Poliol) sendo homogeneizado e em seguida adicionado o isocianato. Após a etapa de polimerização, o poliuretano contendo a enzima (imobilizado) foi mantido durante 24 horas em dessecador para equalização do teor de umidade, para posterior medida da atividade, comparando a enzima na sua forma livre.

\subsection{Avaliação da estabilidade térmica da PMGL imobilizada}

A fim de determinar a estabilidade das enzimas imobilizadas frente a diferentes temperaturas estas foram submetidas a temperaturas de $-80,-2,2-8,10-25$ e $35{ }^{\circ} \mathrm{C}$, respectivamente. 


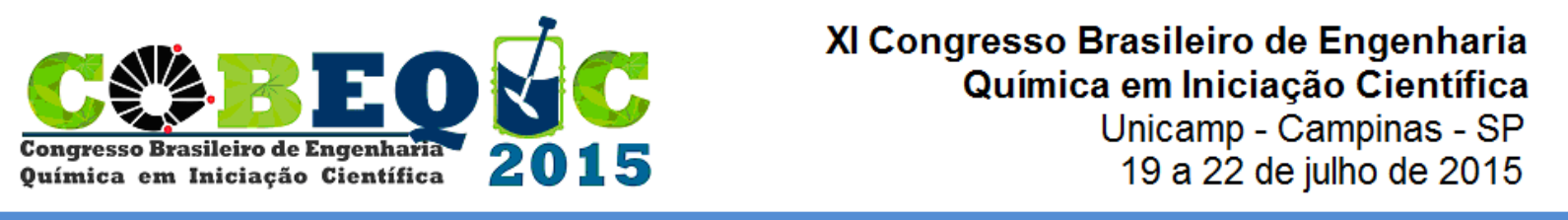

\subsection{Atividade de pectina liase (PMGL)}

A atividade da pectina liase será determinada segundo método de Ayers et al. (1966), descrito por Pitt (1988) com modificações. O método determina os produtos insaturados finais da degradação da pectina pelo ácido tiobarbitúrico. A mistura de reação consistiu em $5,0 \mathrm{~mL}$ da solução de pectina $1,0 \%$ em tampão Tris- $\mathrm{HCl} 0,05 \mathrm{M}, \mathrm{pH} 8,5 ; 1,0 \mathrm{~mL}$ da solução de $\mathrm{CaCl}_{2} 0,01 \mathrm{M} ; 1,0 \mathrm{~mL}$ do extrato bruto enzimático e $3,0 \mathrm{~mL}$ de água destilada. Após a incubação por 10 minutos a $30^{\circ} \mathrm{C}$, foi adicionado $0,6 \mathrm{~mL}$ de uma solução de $\mathrm{ZnSO}_{4} 7 \cdot \mathrm{H}_{2} \mathrm{O}$ $9 \%$ em seguida $0,6 \mathrm{~mL}$ de $\mathrm{NaOH} 0,5 \mathrm{M}$. As proteínas precipitadas do substrato não consumido serão removidas por centrifugação (modelo Mikro 20) a $3000 \mathrm{~g}$ por 10 minutos. $\mathrm{O}$ sobrenadante $(5 \mathrm{~mL})$ será adicionado à mistura de $3,0 \mathrm{~mL}$ do ácido tiobarbitúrico $0,04 \mathrm{M}$; $1,5 \mathrm{~mL}$ de $\mathrm{HCl} 0,1 \mathrm{M}$ e $0,5 \mathrm{~mL}$ de água destilada. A mistura será aquecida em banho-maria (Nova Ética) por 30 minutos, resfriada e medida a absorbância à $550 \mathrm{~nm}$. Uma unidade da atividade enzimática é definida como a quantidade de enzima que causa a mudança de 0,01 na absorbância à $550 \mathrm{~nm}$, nas condições do ensaio (Pitt,1988).

\section{RESULTADOS}

\subsection{Produção de Pectina Liase (PMGL)}

A enzima PMGL foi produzida pela cepa de Aspergillus niger ATCC 9642 em meio composto por $32 \mathrm{~g} / \mathrm{L}$ de pectina cítrica, $0,04 \mathrm{~g} / \mathrm{L}$ de sulfato de ferro, $30 \mathrm{~g} / \mathrm{L}$ de extrato de levedura, nas condições de $180 \mathrm{rpm}, 30{ }^{\circ} \mathrm{C}, 60 \mathrm{~h}$ de incubação do meio, $\mathrm{pH}_{\text {inicial }} 5,5 \mathrm{e}$ $5 \times 10^{6}$ esporos $/ \mathrm{mL}$, a qual teve atividade de $8,63 \mathrm{U} / \mathrm{mL}$.

\subsection{Imobilização}

O rendimento do imobilizado $(1042,06 \%)$ foi calculado considerando a atividade total da enzima livre em solução e a atividade total do imobilizado de acordo com a Equação 1 (Pinheiro, 2005).

$$
R I(\%)=\frac{U_{\text {imobilized }}}{U_{O}} \times 100
$$

Onde:

RI (\%) = Rendimento de imobilização;

$\mathrm{U}_{\text {imobilizada }}=$ atividade enzimática no imobilizado;

Uo = atividade da solução enzimática oferecida para imobilização.

\subsection{Estabilidade da PMGL imobilizada em poliuretano frente a diferentes temperaturas de estocagem}

O estudo da estabilidade é importante, pelo fato de permitir observar o comportamento da enzima e quanto de sua atividade inicial é mantida ao longo do período de armazenamento. 


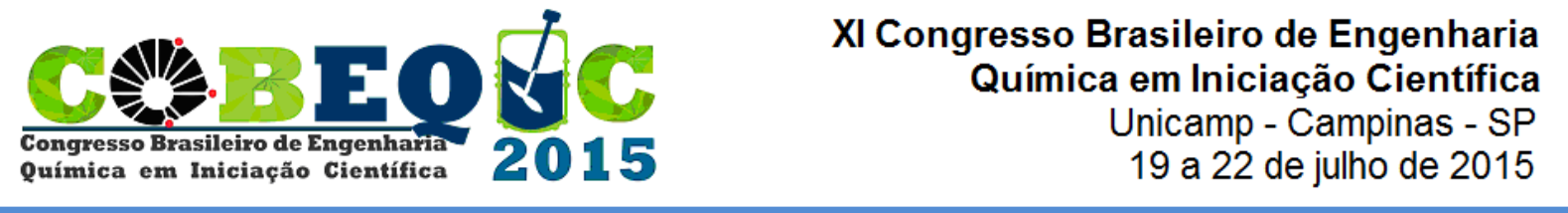

A enzima PMGL imobilizada foi submetida a diferentes temperaturas (-80, -2, 2-8, 10-25 e 35

$\left.{ }^{\circ} \mathrm{C}\right)$ conforme apresentado nas Figuras 1(a), (b), (c), (d) e (e), respectivamente.

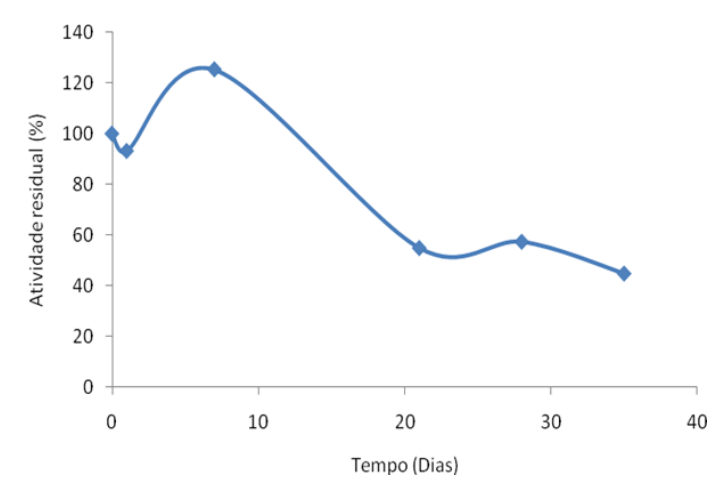

(a) temperatura de $-80^{\circ} \mathrm{C}$.

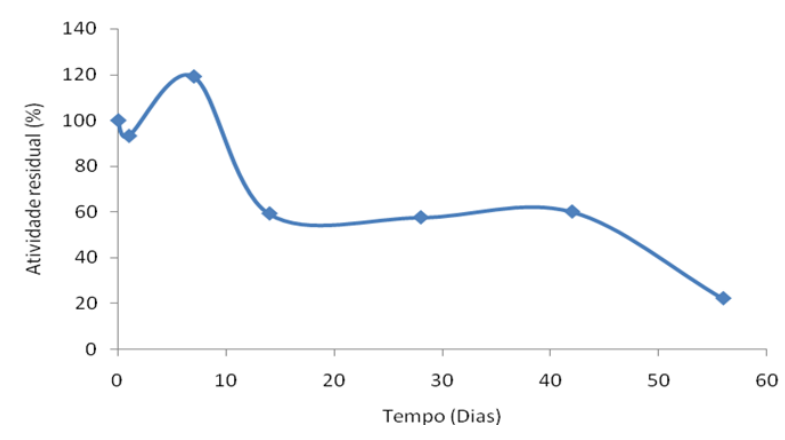

(c) temperatura na faixa de 2 a $8^{\circ} \mathrm{C}$.

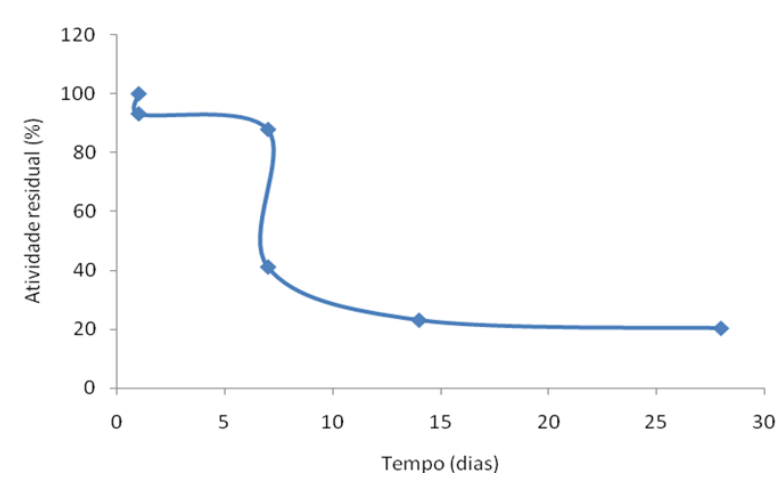

(b) temperatura de $-2^{\circ} \mathrm{C}$.

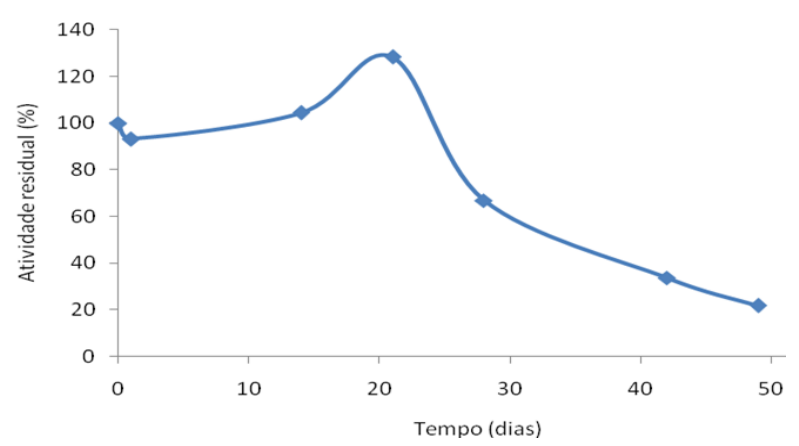

(d) temperatura na faixa de 10 a $25^{\circ} \mathrm{C}$.

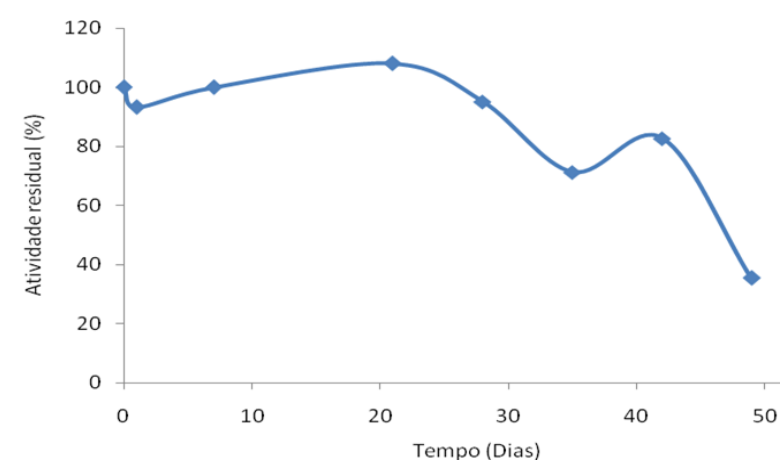

(e) temperatura de $35^{\circ} \mathrm{C}$.

Figura 1- Estabilidade da PMGL imobilizada em poliuretano submetida a diferentes temperaturas $\left(-80,-2,2-8,10-25\right.$ e $\left.35^{\circ} \mathrm{C}\right)$.

De acordo com os resultados apresentados na Figura 1 (a), podemos observar que no tempo de 20 dias a enzima imobilizada atinge $50 \%$ de sua atividade inicial a temperatura de $80^{\circ} \mathrm{C}$, já na Figura 1 (b) quando a PMGL imobilizada foi submetida a temperatura de $-2^{\circ} \mathrm{C}$, onde observamos que já em 5 dias a enzima perde $50 \%$ da sua atividade inicial.

Quando a enzima PMGL imobilizada foi submetida a uma faixa de temperatura igual a 2 a $8^{\circ} \mathrm{C}$ (Figura $1(\mathrm{c})$, sua estabilidade foi de aproximadamente 10 dias a enzima perde $50 \%$ da 
sua atividade inicial. Já quando submetida a outra faixa de temperatura, de 10 a $25^{\circ} \mathrm{C}$ (Figura 1(d), observamos em 40 dias a enzima perde $60 \%$ da sua atividade inicial.

A Figura 1 (e), apresenta a estabilidade da PMGL submetida a temperatura de $35^{\circ} \mathrm{C}$, onde em aproximadamente 50 dias a enzima perde $60 \%$ da sua atividade inicial. Sendo assim, podemos concluir de que a PMGL quando submetida a temperatura de estocagem igual a $35^{\circ} \mathrm{C}$ é mais estável ao longo do tempo quando comparada as demais, ou seja, demora mais tempo para perder sua atividade residual.

Apesar de serem escassas as informações da literatura para avaliação da estabilidade térmica da pectina liase obtida a partir de micro-organismos imobilização em poliuretano.

Busto et al., (2010), ao imobilizar Poligalacturonase (PG) sobre esferas de polimetacrilato-divinilbenceno (pm-dvb), obtiveram resultado semelhante ao do presente estudo, onde a PG imobilizada reteve aproximadamente 70,5 \% da sua atividade após dois meses de armazenamento.

Bampi (2010), estudou a imobilizaçãoda Poligalacturonase (pectinase) de Penicillium brasilianum em suporte de alginato-carvão e observou que, uma queda de atividade de mais de $50 \%$ após $67 \mathrm{~h}$ de armazenamento a $4{ }^{\circ} \mathrm{C}$.

\section{CONCLUSÃO}

De acordo com os resultados apresentados, a pectina liase produzida por $A$. niger ATCC 9642 e imobilizada em poliuretano é mais estável a temperatura de $35^{\circ} \mathrm{C}$, apresentando $50 \%$ de sua atividade após 50 dias de estocagem.

\section{AGRADECIMENTOS}

Os autores agradecem a Uri Erechim, FAPERGS, CAPES e CNPq pelo apoio financeiro.

\section{REFERENCIAS}

AYERS, W. A.; PAPAVIZAS, G. C.; DIEM, A. F. Polygalacturonate trans-eliminase and polygalacturonase production by Rhizoctonia solani. Phytopathology, 56, 1006-1011, 1966.

BUSTOS, M.; ORTEGA, N.; PILAR-IZQUIERDO, M.; PALACIOS, D.; PEREZ-MATEOS, M. Immobilizations of poligalacturonase on pm-dvb beads for oenological applications. Journal of Biotechnology (Special Abstracts), v. 150S, p. S301-S302, 2010.

DÍAZ, A.B; ALVARADO, O.; ORY, I.; CARO, I; BLANDINO, A. Enhance hidrolytic enzymes production by Aspergillus awamori on supplenmented grape pomace. Food and bioproducts processing, v. 91, n. 4, p. 580-586, 2013.

GOMES J., ZENI J., CENCE K., TONIAZZO G., TREICHEL H., VALDUGA E. Evaluation of production and characterization of polygalacturonase by Aspergillus niger ATCC 9642. Food and Bioproducts Processing, 2011.

GOMES, F.; DE PAULA, A.; SILVA, G e DE CASTRO, H. Determinação das propriedades catalíticas em meio aquoso e orgânico da lipase de Cândida rugosa imobilizada em celulignina quimicamente modificada por carbonildiimidazol. Química nova, v. 29, n. 4, p. 710-718, 2006. 
NYARI, N. L. D. Estudo da Imobilização de Lipase de Candida antarctica B em Poliuretano. Dissertação (Mestrado em Engenharia de Alimentos) Universidade Regional Integrada do Alto Uruguai e das Missões - URI, Erechim, 2013.

PEREZ, E.E.; FERNÁNDEZ, M.B.; NOLASCO, S.M.; CRAPISTE, G.H. Effect of pectinase on the oil solvent extraction from different genotypes of sunflower (Helianthus annuus L.). Journal of Food Engineering, v. 117, p. 393-398, 2013.

PITT, M., Pectin lyase from Phoma medicaginis var. pinodella. In: Methods in Enzymology, 161, 350-354, 1988.

SANDRI, I.G.; FONTANA; R.C.; BARFKNECHT, D.M.; SILVEIRA, M.M. Clarification of fruit juices by fungal pectinases. LWT - Food Science and Technology, v. 44, n. 10, p. 22172222, 2011.

SHELDON, R.A.; VAN PELT, S. Enzyme immobilisation in biocatalysis: why, what and how, Chemical Society Reviews, 42, 6223, 2013.

YADAV, S.; YADAV, P.K.; YADAV, D.; YADAV, K.D.S. Pectin lyase: A review. Process Biochemistry, v. 44, p. 1-10, 2009.

ZHANG, H.; WOODAMS, E.E.; HANG, Y.D. Process Biochemistry, v. 46, p. 1909-1913, 2011.

MILNER, S. E.; MAQUIRE, A. R.; FRANSSEN, M. C. R.; STEUNENBERG, P.; SCOTT, E. L.; ZUILHOF, H.; SANDERS, S. M. P. Immobilised enzymes in biorenewables production. Chemical Society Reviews, 42, 6491, 2013. 